\title{
The Effects of Antioxidant Activity in Gamma-Irradiated Navel orange
}

\author{
Y. J. Cho, K. H. Kim and H. S. Yook \\ Dept. of Food and Nutrition, Chungnam National University, Daejeon 305-764, Korea
}

Gamma irradiation on the food materials has been used in the food industry for the preservation and the sanitation. This study investigated the effects of gamma irradiation of 'Navel' oranges. We especially investigated changes in the Antioxidant Activity of gamma irradiated 'Navel' oranges.

The samples were irradiated at doses of $0,0.4,0.6,0.8,1$ and $1.5 \mathrm{kGy}$. To identify the effects of antioxidant activity in gammairradiated Navel orange, total phenolic content, DPPH radical scavenging activity, ABTS scavenging activity, FRAP and Cu2 + activity, reducing power were investigated.

A

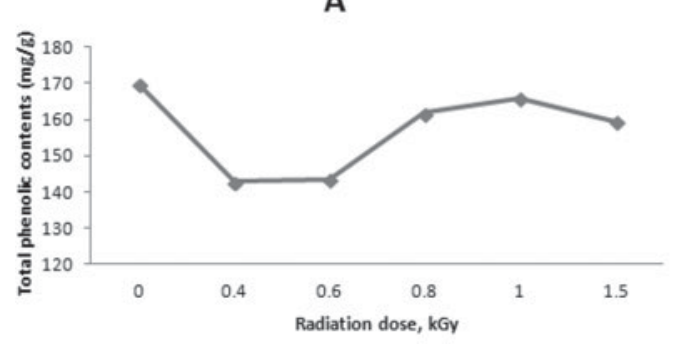

C

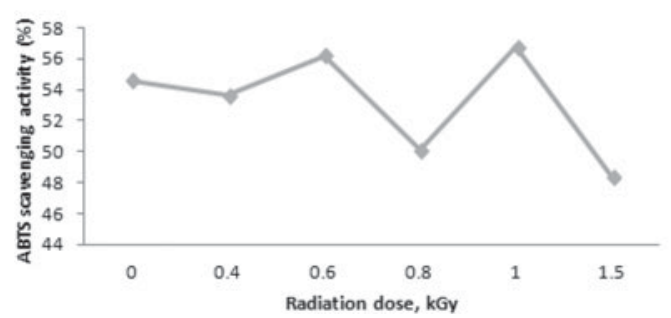

B

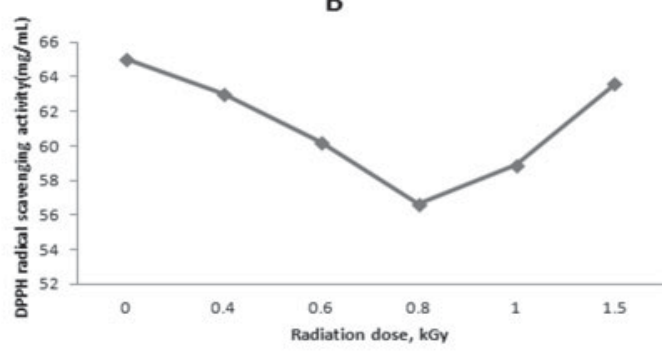

D

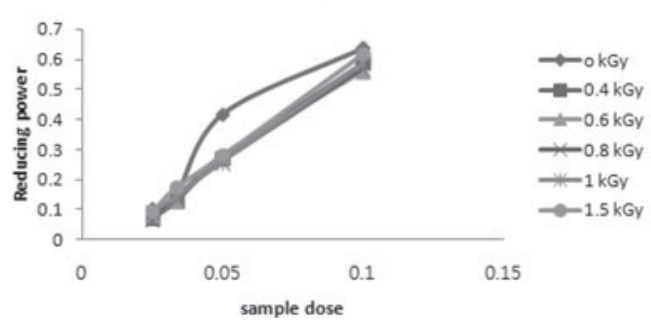

Fig. A, Fig. B, Fig. C, Fig. D. The Effects of Antioxidant Activity in Gamma-Irradiated Orange.

Fig. A shows that the total phenolic contents of gamma irradiated samples were generally low compare to the control. $1 \mathrm{kGy}$ irradiated sample demonstratred the highest measure and it was similar in total phenolic contents to that of control. Irradiated samples had lower DPPH radical scavenging activity than the control $(p<0.05)$, with the sample irradiated at $1.5 \mathrm{kGy}$ having the highest of all irradiated samples which was also similar to that of the control. (Fig. B) Fig. C represents ABTS radical scavenging activity of the samples; 1 kGy irradiated sample was the highest sample. The samples had no significant results in FRAP and $\mathrm{Cu} 2+$ activity between one another, but a sample irradiated at $1 \mathrm{kGy}$ had the most similar activity as with that of control. We found correlativity between reducing power and the dose of the samples; at the same irradiation dosage, reducing power was proportional to the doses of the samples. (Fig. D)

In summary, our data indicate that irradiating Navel oranges at $1 \mathrm{kGy}$ does not negatively impact them as indicated; because it has the similarities of antioxidant activity with the control.

This research was supported by Export Promotion Technology Development Program, Ministry for Food, Agriculture, Forestry and Fisheries, Republic of Korea.

1. Cha YY (2009) Journal of Society of Korean Medicine for Obesity Research 9(2), 57-63.

2. Choi JI, Kim HJ \& Lee JW (2011) Korean Society for Biotechnology and Bioengineering Journal 26, 565-568.

3. Brandstetter S, Berthold C, Isnardy B, Solar S, Elmadfa I (2009) Food and Chemical Toxicology 47(9), 2230-235. 